\title{
It's a Pleasure to Meet You
}

\author{
Dr. Sandra Wilson \\ University of Dundee \\ Nethergate, Dundee DD1 $4 \mathrm{HN}$ \\ s.z.wilson@dundee.ac.uk
}

\author{
Lilia Gomez Flores \\ University of Dundee \\ Nethergate, Dundee DD1 4HN \\ l.gomezflores@dundee.ac.uk
}

\author{
Douglas Kinnear \\ University of Dundee \\ Nethergate, Dundee DD1 4HN \\ d.z.kinnear@dundee.ac.uk
}

\begin{abstract}
The need to identify ourselves has become part of our everyday lives; we constantly need to authenticate and validate who we are both to other human beings and more recently to machines to gain access to buildings, products and services. The public has responded to this need for authentication in unexpected ways, for instance the introduction of a new British ID card had to be stopped as result of public and political resistance (Whitley and Hosein, 2009); a contrast with the fact that it is the same British public who have been eager adopters of loyalty cards schemes (Lacey and Sneath, 2006). While it is undeniable that disclosing personal information can have negative consequences and people have been warned to be careful about it, this paper will explore some of the pleasurable and delightful experiences that users have as a result of managing their identities while interacting with different artefacts and technologies. A series of pleasurable experiences with loyalty schemes are considered to contrast with a variety of smart design devices and wearable technologies that address our deeper personal and emotional values.
\end{abstract}

Identity Management, Art \& Design, Wearable Technologies, Interactivity, smart devices, premediation

\section{INTRODUCTION}

Not so long ago authentication was a straightforward process based on direct contact and recognising someone by visual appearance. Nowadays much of our contact is remote and so to identify a person has become more complicated. It involves the use of computers, devices and different technologies to communicate who a person is and to validate their identity often resulting in unpleasant experiences. Authentication is the process of positively verifying the identity of a user, device, or other entity in a computer system, often as a prerequisite to allowing access to resources in the system (O'Gorman, 2003).

Identity Management (IM) is the enrolment and subsequent verification (i.e. the decision made as a result of authentication) that gives individuals a trusted means to prove who they are to others (www.scotland.gov.uk). Lately with Identity Theft becoming an issue, governments and institutions are making efforts to educate people on how much information they disclose and to whom.

\section{FORMS OF IM}

There are mainly three forms of IM, these are based on knowledge/memory, tokens and body related systems. Knowledge/memory forms include passwords and pin codes - single words, phrases or numbers that people have to remember and keep as a secret (Pond, R. et al., 2000). A token is a physical portable artifact that performs or aids authentication (Weiss, K.P. et al. 1988) such as a passport, driving license, etc. Body based forms or Biometrics are features measured from the human body that are distinguishing enough to be used for user authentication. Biometrics includes: fingerprints, eye, face, hand, voice, and signature, as well as other more obscure or futuristic such as gait and smell (Bolle, R.M. et al. 2003).

Pop culture has shaped expectations and perception regarding IM through books and films that offer a twisted reality of what it means to trust governments and organizations with our personal data and identity information. Minority Report (Dreamworks 2002), The Bourne Trilogy (Universal Pictures 2002 - 2007) and The Net (Columbia Pictures 1995) portray the abuse of the authorities and the victimization of the main characters. The news has also played an important role with sensationalist stories about identity theft, and sharing personal information online with applications like takethislollipop. Beyond this, these books, TV shows, graphic novels and films premediate our expectations of the future.

According to Grusin (2004) the logic of premediation insists that the future itself is already mediated, and that with the right technologies the future can be remediated before it happens. 


\section{MAKING THE PROCESS OF IDENTIFICATION A DELIGHTFUL EXPERIENCE}

With all the negative press IM has, it is a challenge to create enjoyable and pleasurable experiences related to it; however there are some products and services that have managed to do so. Through the use of technology they engage people to do IM in more dynamic and pleasurable ways.

\subsection{Loyalty Schemes}

Loyalty cards (Tesco Clubcard), in-store loyalty kiosks (Boots), and reward programs (American Express Air Miles) are some examples that require people to disclose personal information such as name, address, date of birth, bank details, post code; and sometimes they also require them to create an online ID which can be used to claim discounts or rewards. Even when it takes time and effort to fill in online forms and applications in sometimes very unfriendly websites, people do it. These schemes are about the collection and management of information through different technologies.

\begin{abstract}
"In a bonus programme, the bonus is the price for the information that I get. I buy knowledge through it, not loyalty, because loyalty is not purchasable". (Jenkinson, 1995)
\end{abstract}

The success of these marketing strategies is based on what O'Brien and Jones (1995) defined as customer values:

(i) Cash Value. Giving personal information or creating on-line IDs because of cash reward perceived.

(ii) Choice. Giving personal information and creating on-line IDs on a voluntary basis contrary to what happens sometimes with government and official institutions where there is a forced feeling to it.

(iii) Aspirational Value. Disclosing personal information and habits to be part of a 'selected' and 'valued' club of customers.

(iv) Relevance. Disclosing personal information to companies and websites that are relevant to an occupation or lifestyle.

(v) Convenience. Creating on-line IDs as a convenient way to save time when using repeatedly the same website or service.

Through a token (usually a card) people will identify themselves as loyal customers when purchasing products or services and be rewarded with points, vouchers, air miles etc. tailored specifically for them. It is the promise of these 'personal' rewards that makes the experience and the interaction enjoyable. Consumers achieve both psychological and economic benefits from a loyalty program in the redemption stage (Liu, 2007). The sense of being important enhances customers' sense of well-being. Some researchers have proposed that there is another psychological benefit, the opportunity to indulge in luxuries (e.g. American Express and British Airlines work together to offer loyal customers points to upgrade their flight tickets). All these benefits and sense of being appreciated start after voluntarily disclosing personal information to favourite brands.

Recent developments in design however have not adopted a marketing based approach often associated with new products. Within design pleasurable experiences are related not with a cash or aspirational value but with deeper personal and emotional values.

\section{2 'Smart' Devices \& Wearable Technologies}

There is currently much activity in developing smart jewellery and smart textiles. Such wearable technologies are closely related to wearable computers and to ubiquitous computing. The aim is to seamlessly interweave technology into people's everyday lifestyle and into their bodies and personal space.

\begin{abstract}
"A smart device is an electronic device that is cordless (unless while being charged), mobile (easily transportable), always connected (via $\mathrm{WiFi}, 3 \mathrm{G}, 4 \mathrm{G}$ etc.) and is capable of voice and video communication, internet browsing, 'geolocation' (for search purposes) and that can operate to some extent autonomously."(Posland, 2009)
\end{abstract}

To access all these smart devices and services, people usually need to authenticate who they are uploading into different systems personal information that will create a virtual identity linking the real person to the wearable technology. A few products and services have managed to transform the tedious experience of having to create and validate yet another identity into something pleasurable and enjoyable.

\subsubsection{Rumbatime}

Rumbatime is a fashionable collection of watches designed using an RFID (Radio Frequency Identification) tag specifically designed for people with a very active lifestyle such as surfers, runners, clubbers, etc. The integrated tag can be loaded with credit/debit card information to be used with contact less payment technology. The user will create an online ID and will validate it using credit/debit card details not having to worry about carrying a bag, purse or wallet, and then enjoying the freedom of pursuing their favourite sporting activity for example; whilst in this way personal hobbies and interests are prioritised over just being a consumer. 


\subsubsection{Emergency Medical Alert (EMA) Jewellery}

People wear medical alert jewellery when they have hidden health issues such as diabetes, medical implants, severe allergies, etc. The jewellery is usually marked with an obvious medical symbol and holds, in a variety of ways, information intended to assist health professionals should the wearer be unable to communicate. Wearers have reported that they dislike the available designs; prominent medical symbols mean that it is possible for anyone to see that there is a health issue. Sometimes the jewellery holds paper with written information about the patient or the nature of the health issue stamped on it. These designs tend to be bulky and unattractive and can quickly become out dated or unreadable due to water ingress.

Jewellery fitted with an RFID tag can be worn without the need for medical symbols or any other identifying marks combining the technology with the patients existing jewellery, or purchasing preembedded within new jewellery. The wearer will choose the jewellery and so will obviously be happy to wear it, as it will be personalised for them. The RFID tag would contain a unique ID number; national registers would be kept of tags issued and details of the recipient recorded against the unique ID numbers. Patients can have any number of tags, however, they would all contain the same unique identifier. This jewellery transforms the experience from something that can be a stigma for the wearer into a pleasurable experience.

\subsection{Social Networks and Virtual Communities}

Lately it seems that nothing says 'this is me' like social networks. Terms such as Life Logging, Lifecatching, etc. define the social act of storing and sharing life events using a public forum, usually using social networks (wikipedia.org). In an attempt to simplify the process of identification and to link information, social networks such as Facebook, Twitter, Google, MySpace and Pinterest are being used as an online ID people can use to sign in around the web. From sports to reality TV shows to music and films, $90 \%$ of Internet users logging into entertainment sites using their social network ID. These websites incorporate different social features like Live Chat, Opinion Polls and Special Promotions to encourage people to interact with existing networks of friends to make the experience much more pleasurable.

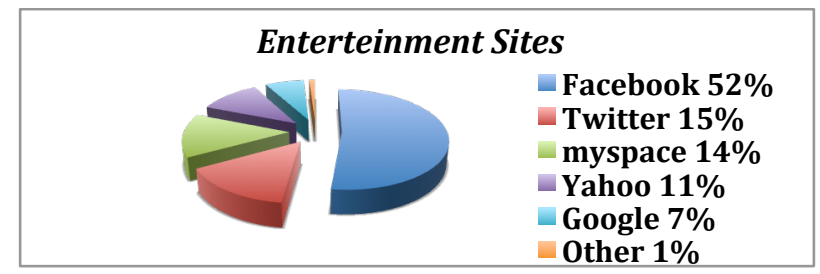

Source GIGYA.COM Data from month ending May 2010
Figure 1: Social Networks being used for ID purposes

Some interactions are now mixing smart garments with social networks trying to enhance the experience for users. Ping is a garment that connects to a Facebook account wirelessly and from anywhere without using a phone or laptop. It allows users to stay connected to friends and groups of friends simply by performing natural gestures that are built into the mechanics of the garment. Lifting up a hood, tying a bow, zipping, buttoning, and simply moving, bending and swinging ping friends naturally and automatically (electricfoxy.com).

A different but not less entertaining way of IM is through Virtual Communities (VCs) in the Internet where users from all over the world can log in, create and manage as many different identities as they want. People take a lot of pleasure and pride in creating, maintaining and upgrading their avatars; graphic representations of a person in a computer game (Cooper, R., 2007). VCs such as World of Warcraft and Second Life allow users to create and shape identities that can be as close or far from the real ones, and to interact with other avatars on many different playful and pleasurable ways. Through virtual IDs users can be sorcerers on a quest, rescue a team member, fight for gold, or be themselves and go with virtual friends to concerts or clubbing, get married and have virtual babies, the possibilities for having fun and enjoying their virtual selves are almost infinite.

\subsection{Future generations and IM}

IM will have a different connotation for future generations, Internet websites and applications such as kidmondo.com, tweekaboo.com, babimia.com and Google encourage parents to keep an online diary of everything relevant in the lives of their babies starting from the moment they are born (or even before when possible). Parents will take pictures; movies and record sound keeping a detailed description of all the joyful moments that shape their babies' identities. They can do all these using smart phone apps and uploading everything online. It is too soon to know how identity, privacy and trust will be perceived by future generations but there is no doubt that for a lot of parents, grandparents, family members and friends it is a delightful experience to be able to easily record, store and share every moment of their babies lives.

Children's movies too are premediating IM for future generations through a more playful lens. 3D animated movies such as Monsters Inc. (Disney Pixar, 2001), Despicable Me (Universal Pictures 2010), Megamind (Dreamworks, 2010) and The Incredibles (Disney Pixar, 2004) are some 
examples of showing IM as a cool, enjoyable, funny experience that is part of the daily lives of the 3D characters and one that will be part of everybody's routine very soon.

\section{CONCLUSIONS}

Digital Natives (ie those born after 1980) have grown up used to instant gratification, frequent and almost immediate rewards. Today's average college graduates have spent less than 5,000 hours of their lives reading, but over 10,000 hours playing video games (not to mention 20,000 hours watching TV). Computer games, email, the Internet, cell phones and instant messaging are integral parts of their lives, it is easier to engage them through games than serious 'work' or 'objects' (Prensky, 2001). The challenge for governments, institutions, policy makers and mainly designers is to create objects, technologies and services that allow this generation to manage their identity without loosing their individuality, to define who they are beyond the data allowing them to express personal value systems attaching emotional and aesthetic value.

The examples used in this paper show how IM can become an engaging practice for the public if a pleasurable, joyful and fun experience can be found at the centre of the interaction.

Social networks such as Pinterest give us the opportunity to create a visual ID to share part of who we are through the use of images and videos in a more enjoyable way.

Designers are transforming what used to be part of a data driven need into a more human oriented, delightful experience, proving that IM can be about people's emotions and personal values rather than just about information. Through different technologies, products and services we now can validate, manage and celebrate who we are not just in the material world but also in virtual and imaginary ones.

\section{REFERENCES}

Bolle, J R. M., et al. (2003) Guide to Biometrics: Selection and System Design. Springer-Verlag, New York.

Gigya.com. (2011) Social Identity: 7 Best Practices for Driving Registrations, www.gigya.com (retrieved June 2012)

Grusin, R. (2004) Premediation. Criticism, vol. 46, no. 1, pp17-39.

Jenkinson, A. (1995) Retailing and shopping on the Internet. International Journal of Retail \& Distribution Management, Vol. 24 No. 3, pp. 26-37.
Jennings (Ed); Zillmann, Dolf (Ed) Media effects: Advances in theory and research (2nd ed.).LEA's communication series. Lawrence Erlbaum Associates Publishers, Mahwah, NJ, US

Liu, C. (2007) Modeling Consumer Adoption of the Internet As a Shopping Medium: An Integrated Perspective. Library of the Congress, US

Mann, S. (2001) Wearable Computing: Toward Humanistic Intelligence. IEEE Intelligent Systems, vol. 16, no. 3, May/June 2001, pp. 10-15.

McCombs, M., Reynolds, A. B., (2002) News influence on our pictures of the world.

O'Brien, L. and Jones, C. (1995) Do rewards create loyalty?. Harvard Business Review, Vol. 73 No. 3, pp. 75-83.

Pond, R., Podd, J., Bunnell, J., and Henderson, R. (2000) Word association computer passwords: The effect of formulation techniques on recall and guessing rates, Computing Security, vol. 19, no. 7, pp. 645-656,

Poslad, S. (2009) Ubiquitous Computing: Smart Devices, Environments and Interactions, John Wiley \& Sons, US

Prensky, M. (2001) Digital Natives, Digital Immigrants, On the Horizon, Vol. 9 Iss. 5, pp. 1-6

Rowley, J. (2000) Loyalty kiosks: making loyalty cards work. British Food Journal, Vol. 102 Iss: 5 pp. $390-398$.

Sang, M. J. (2008) The Influence of Perceived Loyalty Program Value on Satisfaction, Switching Costs, and Attitudinal and Behavioral Loyalty: An Empirical Investigation of a Casino Loyalty. Michigan State University, U.S.A.

The Scottish Government. (2011) Identity Management and Privacy Principles Privacy and Public Confidence in Scottish Public Services. www.scotland.gov.uk/Resource/Doc/16999/011000 2.pdf (retrieved June 2012)

Weiss, K. P. (2006) Method and apparatus for positively identifying an individual. By Bruce Christianson, Bruno Crispo, James A. Malcolm (eds). Security Protocols: 14th International Workshop, Cambridge, UK, March 2006. Springer, Cambridge.

Whitley, E. (2009) Perceptions of government technology, surveillance and privacy: the UK Identity Cards Scheme. Goold, B. J. and Neyland, D. (eds). New Directions In Surveillance And Privacy. Wiliam Publishing, Devon. 